\section{NO. 160}

DECEMBER

2020

\section{KEY POINTS}

- The impact of the coronavirus disease on businesses in Mongolia has been severe; smaller businesses were hit harder than larger ones.

- Falling demand, working capital shortages, cash flow disruptions, and limited access to finance were key challenges.

- Businesses reacted by reducing costs, laying off workers, and among micro and informal businesses, by reducing household expenditure.

- Few micro, small, and mediumsized enterprises and informal businesses were exploring opportunities to adapt.

- Policies with the highest level of support included tax exemptions that enabled businesses to maintain liquidity.

- Limited action to enable access to finance was a key gap in the initial government response.

- Options for sustainable recovery include (i) support mechanisms to preserve liquidity and enhance access to finance; (ii) support the specific needs of women entrepreneurs; (iii) enable digital transformation; (iv) support the formalization of informal businesses; and (v) communicate and engage with micro, small, and mediumsized enterprises and informal businesses on the design of subsequent measures.

\section{Sustainable Recovery Options for Mongolia's Micro, Small, and Medium-Sized Enterprises}

\author{
Veronica Mendizabal Joffre \\ Social Development Specialist \\ (Gender and Development) \\ East Asia Department \\ Asian Development Bank
}

\author{
Bolormaa Luvsandorj \\ Managing Partner \\ Bodhi Financial Advisory Services LLC
}

\section{INTRODUCTION}

Micro, small, and medium-sized enterprises (MSMEs) are one of the most dynamic sectors in Mongolia. This sector comprises 77\% of total registered business entities, $72 \%$ of total workforce, $17.8 \%$ of gross domestic product, and $2.3 \%$ of total exports. ' Women make up a large share of MSME entrepreneurs in Mongolia. ${ }^{2}$ Most MSMEs operate in the trade (51\%) and services sectors (32\%), followed by manufacturing (19\%) and agriculture (6\%). ${ }^{3}$ The informal economy in Mongolia is estimated to contribute from $9.2 \%$ to $15.7 \%$ of gross domestic product. ${ }^{4}$

This brief benefited from the insightful comments provided by Xiaogin Fan, director, and Aziz Haydarov, senior financial sector specialist, East Asia Financial Management Division, East Asia Regional Department (EARD). Declan Magee, senior country economist; Tsolmon Begzsuren, senior social development officer (Gender); Bold Sandagdorj, senior economics officer; and Enerelt Enkhbold, senior investment officer at the Mongolia Resident Mission, and Akiko Terada-Hagiwara, principal economist, EARD, likewise provided invaluable comments. Keiko Nowacka, Senior Social Development Specialist (Gender and Development), Sustainable Development and Climate Change Department; and Anne Valko Celestino, Social Development Specialist (Gender and Development), Private Sector Operations Department, peer reviewed the manuscript. This study was conducted under Regional Technical Assistance TA-9540 Enhancing Gender Equality Results in East Asia. The Asian Development Bank collaborated with the Women Entrepreneur Council at the Mongolian National Chamber of Commerce in carrying out the survey. National Program on SME Sector Promotion (approved in 2019 through Cabinet Resolution No. 156); and L. Boojoo. 2019. Leveraging SME Finance through Value Chains in the CAREC Landlocked Economies: Case of Mongolia. ADBI Working Paper Series. No. 1019. Tokyo: Asian Development Bank Institute.

2 The International Finance Corporation estimated that in 2014, women-owned MSMEs constituted about $60 \%$ of this segment in Mongolia (International Finance Corporation [IFC]. 2014. SMEs and Women-Owned SMEs in Mongolia. Washington, DC).

3 National Statistics Office. 2019. Business Registry Report 2018. Ulaanbaatar. https://1212.mn/ BookLibraryDownload.ashx?url=BR-Taniltsuulga-2018.pdf\&ln=Mn.

4 National Statistics Office. 2020. Shadow Economy Research and Calculation 2015-2018. Ulaanbaatar. http://1212.mn/BookLibraryDownload.ashx?url=NOE_2015-2018.pdf\&ln=Mn.
ISBN 978-92-9262-588-7 (print) ISBN 978-92-9262-589-4 (electronic) ISSN 2071-7202 (print) ISSN 2218-2675 (electronic) Publication Stock No. BRF200391-2 DOI: http://dx.doi.org/10.22617/BRF200391-2 
Under normal circumstances, MSMEs and informal entities face several challenges, including a chronic gap in access to finance. How were these businesses affected by the combined health and economic crises brought about by the coronavirus disease (COVID-19)? What are the options for their recovery?

This brief presents the findings from a rapid assessment of impacts of COVID-19 on Mongolian MSMEs and informal businesses conducted by the Asian Development Bank from 15 April to 30 May 2020. It proposes options to make ongoing and future economic recovery measures inclusive and responsive to the needs of this key economic segment.

\section{SURVEY DESIGN AND RESPONDENT PROFILE}

Throughout the document we refer to MSMEs as registered enterprises, and use the term "informal" to indicate sole proprietor, unincorporated, or unregistered businesses. In this brief, we use the definition of MSMEs as stated in the Law of Mongolia on Support of Small and Medium Enterprises and Services (2019). ${ }^{5}$ Mongolia does not have an official definition of women-owned enterprise, and we use the well-accepted definition provided by the International Finance Corporation (IFC 2020). ${ }^{6}$

The assessment was conducted in three phases using mixed methods, including virtual and paper-based surveys in urban and rural areas. In phase 1, an online survey was conducted targeting MSME members of the Women Entrepreneurs Council of the Mongolia National Chamber of Commerce and Industry (MNCCl) from 15 April to 6 May 2020. In phase 2, the survey was expanded to include entrepreneurs in the informal economy in markets in Ulaanbaatar and Nalaikh districts. Given the difficulties in reaching this sector through online methods, the survey was conducted using face-to-face paper-based surveys from 11 to 15 May. In phase 3, a paper-based survey was conducted among MSMEs and informal businesses in towns and rural areas in nine provinces from 21 to 29 May. ${ }^{7}$

The survey questionnaire consisted of five parts: (i) basic respondent information on the business (e.g., size, sector, ownership), (ii) key business challenges resulting from the COVID-19 crisis, (iii) coping mechanisms, (iv) assessment of government responses to support businesses, and ( $v$ ) suggestions on potential measures to assist businesses during and beyond the pandemic.

A total of 1,003 respondents participated in the survey, of which $59.5 \%$ were women entrepreneurs. Registered MSMEs accounted for $28 \%$ of the respondents, and unincorporated businesses (sole proprietor or informal, whether micro or small) comprised the remaining $72 \%$. Rural businesses made up $56 \%$ of the sample. By firm size, using total revenue as criterion, micro entities made up $94.6 \%$ of the sample, small entities $3.9 \%$, medium-sized entities $0.8 \%$, and large entities $0.7 \%$. Of the total, $41 \%$ belonged to the trade sector, followed by services (31\%), manufacturing (14\%), and other sectors (14\%) (Figure 1).

\footnotetext{
Figure 1: Respondent profile

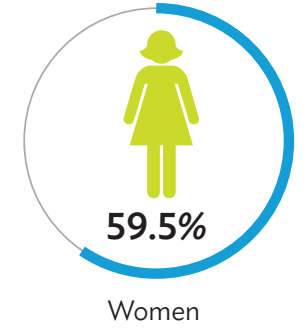

entrepreneurs

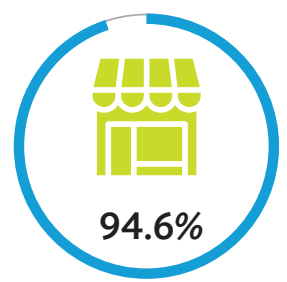

Micro enterprises

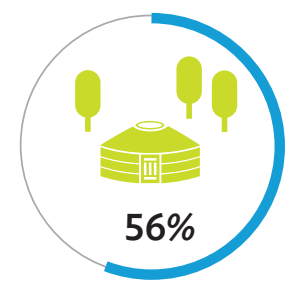

Rural enterprises

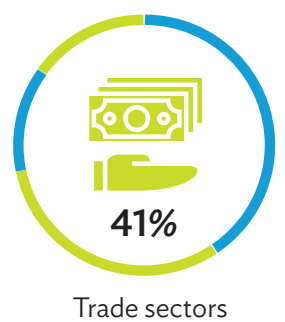

followed by services (31\%), manufacturing (14\%), and others (14\%)

Source: Asian Development Bank East Asia Department.

5 The revised Law of Mongolia on Support of Small and Medium Enterprises and Services (2019) defines micro industry and service provider as a business entity with up to 10 employees, operating in the production, trade, and services sector, with annual sales income of up to MNT300 million. Small enterprise and service provider means a business entity with 10-50 employees, operating in the production, trade, and services sector, with annual sales revenue of MNT300 million to MNT1 billion. Medium-sized enterprise and service provider means a business entity with 50-200 employees, operating in the production, trade, and services sector, with annual sales revenue of MNT1 billion to MNT25 billion. Ministry of Justice and Home Affairs, Central Legal Information System https:// www.legalinfo.mn/law/details/14525.

6 An enterprise qualifies as a woman-owned enterprise if it meets the following criteria: (a) $\geq 51 \%$ owned by woman/women or (b) $\geq 20 \%$ owned by woman/ women; and has (i) $\geq 1$ woman as Chief Executive Officer/Chief Operating Officer/President/Vice President and (ii) $\geq 30 \%$ of the board of directors composed of women, where a board exists. IFC 2020. IFC Definitions of Targeted Sectors. https://www.ifc.org/wps/wcm/connect/industry_ext_content/ifc_external_ corporate_site/financial+institutions/priorities/ifcs+definitions+of+targeted+sectors

7 The provinces include Arkhangai, Dornod, Dornogobi (including Zamiin Uud town on the border with the People's Republic of China), Gobi-Altai, Khovd, Sulkhbaatar, Umnugobi, Uvs, and Zavkhan.
} 
The findings provide an approximation of the impacts of the COVID-19 crisis on MSMEs and the informal business sector, and fill a gap in knowledge on these economic segments. Nonetheless, findings are not based on a representative sample as data collection was restricted due to the emergency situation and nonstandard sampling procedures used. To address the potential bias given the nonstandard sampling procedures, some of the survey results were compared with the results of a survey conducted by $\mathrm{MNCCl}$ in March 2020 among its member companies. ${ }^{8}$ The $\mathrm{MNCCl}$ survey provides information to assess the overall impact of the pandemic on businesses in Mongolia, focusing on formal and larger entities in urban centers, except informal businesses.

\section{SURVEY RESULTS}

The Government of Mongolia reacted early on to prevent the spread of COVID-19, and was highly successful in containing the medical emergency. ${ }^{9}$ Measures included travel bans, border closures, social distancing measures, cancelled public events, and closure of schools and universities.
However, preventive measures led to varying levels of economic stress among the business sector and MSMEs, with informal enterprises severely affected. Impacts included a sharp fall in revenue as reported by $77 \%$ of MSMEs and $65 \%$ of informal businesses, leading to declining liquidity and cash flow problems for $44 \%$ of MSMEs and $45 \%$ of informal entities. Supply-chain impacts caused by border crossing restrictions were felt by a high share of MSMEs (72\%), although this affected less than a quarter of the informal respondents. Likewise, while $53 \%$ of the surveyed MSMEs indicated reduced demand for their services and products, only $23 \%$ of informal businesses reported declines in demand. Liquidity issues in turn weakened the capacity of enterprises to (i) cover fixed costs including loan and interest payments for 38\% of MSMEs and $43 \%$ of informal businesses surveyed; (ii) pay salaries and wages for $35 \%$ of MSMEs and $18 \%$ of informal business; and (iii) pay rent and basic services, particularly among informal entrepreneurs (49\%) and almost a third (29\%) of MSMEs (Figure 2).

A high share of female MSME entrepreneurs indicated declines in revenue. Compared to $50 \%$ of male entrepreneurs surveyed, $85 \%$ of female respondents reported supply chain issues such as

Figure 2: Key Impacts of the Coronavirus Disease on Mongolian Micro, Small, and Medium-Sized Enterprises and Informal Businesses, May-June 2020 (\%)

Impacts

Decline in revenues

Shortage of raw materials; issues with logistics and transportation

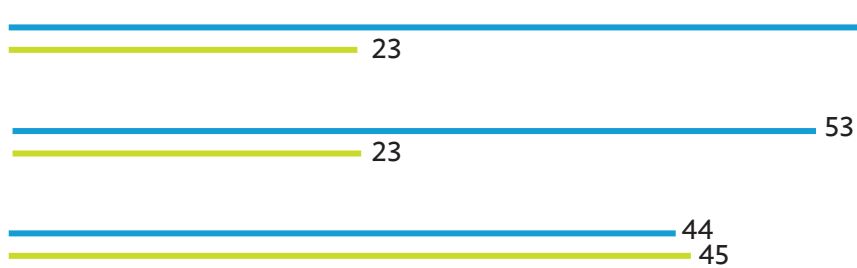

Could not repay loans and interest

Could not pay their employees

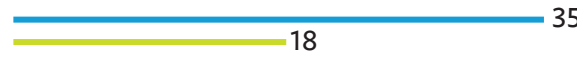

Could not pay rent and basic services (electricity, internet, water)

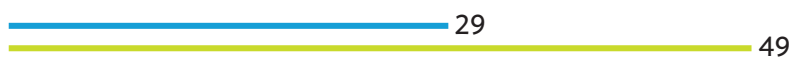

No funding sources for investment

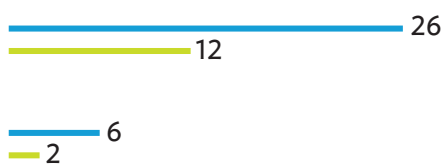

Micro, small, and medium-sized enterprises $(\mathrm{N}=280)$

No change $\quad-2$ Informal businesses ( $\mathrm{N}=723)$

$\mathrm{N}=$ Total Responses

Source: ADB East Asia Department.

8 Mongolian National Chamber of Commerce and Industry. 2020. MNCCI Survey Report on COVID-19 Impact. Ulaanbaatar. https://www.mongolchamber.mn/ resource/mongolchamber/File/2020/04/06/rczh1ltgksjy9i3n/Sudalgaanii\%20negdsen\%20tailan_20200305.pdf.

9 Six hundred twenty-nine cases have been recorded in Mongolia as of 23 November 2020. 
shortage of raw materials (83\% compared to 34\% among male respondents), and reduced demand for products and services ( $59 \%$ for females versus $31 \%$ for males). Both female- and maleowned enterprises suffered cash flow shortages and difficulties in loan repayment. However, female entrepreneurs indicated slightly less difficulties in paying rent (28\% compared to $31 \%$ of their male counterparts) and in financing their investments (21\% compared to $41 \%$ of male respondents). There were more challenges in paying employees for female entrepreneurs at $37 \%$, versus $28 \%$ of male entrepreneurs), possibly reflecting the higher share of female entrepreneurs in the manufacturing sector in the sample (31\% compared to $6 \%$ among male respondents).

\section{Falls in revenue were also pronounced among urban}

entrepreneurs. Among urban respondents in the informal sector, $92 \%$ indicated loss of revenue compared to $40 \%$ in rural areas. Also, more businesses in urban areas (52\%) indicated difficulties in paying rent, compared to $46 \%$ in the rural areas. Urban areas reported difficulties paying their employees (24\%) in contrast to rural areas (12\%). Both areas indicated cash flow shortages (41\% for urban and $49 \%$ for rural) as well as difficulties with loan repayment (40\% for urban and $45 \%$ for rural).
Impacts on smaller and informal businesses were likely stronger than on larger companies. Comparing the responses from MSMEs and informal businesses to those from a survey of medium-sized and larger enterprises conducted by $\mathrm{MNCCl}$ (footnote 8), smaller businesses appear to have been hit harder in terms of liquidity, financing, and employee reductions. Larger businesses were better able to deal with the shock much longer due to economies of scale and better capital structures (Figure 3).

\section{Declines in revenue affected the livelihood of informal entrepreneurs and led to declines in household consumption. The survey of sole proprietors in urban and rural areas included} questions related to their household income and impact on their livelihood. A total of 600 sole proprietors ( $86 \%$ of surveyed informal entrepreneurs) responded to these questions. The findings indicate reduced household income for $89 \%$ of the respondents, leading to reduced expenditure for food and daily necessities for $55 \%$ of respondents. ${ }^{10}$ In the first quarter of 2020 , household revenue had increased by $12.6 \%$ to MNT1.2 million as a result of the minimum salary increase in January and pension payments in February. However, these gains were offset by increased household expenditure, primarily due to a spike in food prices. ${ }^{11}$

\section{Figure 3: Comparison of Key Challenges Faced by Enterprises Due to COVID-19, 2020 (\%)}

Key challenges

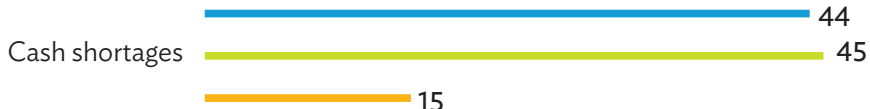

15

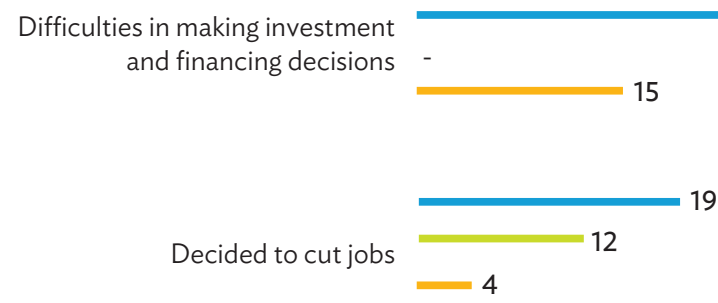

57

ADB survey of micro, small, and medium-sized enterprises, April-May 2020

ADB survey of informal businesses, April-May 2020

MNCCl survey of medium and

large enterprises, March 2020

$\mathrm{ADB}=$ Asian Development Bank; $\mathrm{MNCCl}=$ Mongolian National Chamber of Commerce; MSME = micro, small, and medium-sized enterprises.

Note: The MSME and informal business surveys were conducted by ADB in April-May 2020, while the MNCCI survey of medium and large enterprises was conducted in March 2020.

Sources: ADB East Asia Department; MNCCI. 2020. MNCCI Survey Report on COVID-19 Impact. Ulaanbaatar.

10 A survey on impact of COVID-19 on households by the United Nations Development Program reported a 27\% decrease in food consumptions for all groups, and $41 \%$ decrease in households headed by women, compared to $21 \%$ of households headed by men. The impact of reduced household income appeared more severe on urban households with $70 \%$ of urban respondents reporting reduced expenditure for food and daily necessities, compared to $31 \%$ in rural areas. See UNDP. 2020. Rapid Socio-Economic Impact Assessment of COVID-19 Prevention Measures on Vulnerable Groups and Value Chain in Mongolia. Ulaanbaatar.

1 National Statistics Office of Mongolia and World Bank Group. 2020: Results of Mongolia COVID 19 Household Response Phone Survey (July 2020). http:// documents1.worldbank.org/curated/en/656061595316484647/pdf/Results-of-Mongolia-COVID-19-Household-Response-Phone-Survey-Round-1.pdf. 


\section{COPING MECHANISMS}

\section{Businesses' top priority at the height of the crisis was to} maintain liquidity. By May 2020, over half of the respondents had slashed costs (58\%), and/or scaled back production or service offerings (32\% of MSMEs and $24 \%$ informal entrepreneurs). Some had reduced their number of employees (19\% among MSMEs and $8 \%$ among informal entrepreneurs), which is significantly higher than the $4 \%$ reported among medium and large business in the $\mathrm{MNCCl}$ survey. More women-led businesses, particularly MSMEs, had cut jobs (23\%) compared to men's businesses (8\%). However, about $18 \%$ of the MSME respondents and $12 \%$ of respondents in the informal sector had not taken any measures, with only $1 \%$ closing temporarily. It is interesting to note that few businesses had started exploring alternative business models. Among MSMEs, 19\% had initiated the transition to online operations and online sales, and $11 \%$ were assessing their business model for a post-COVID-19 environment. None of the informal entrepreneurs indicated exploring new ways of doing business to boost demand or adapt to the new circumstances (Figure 4).
Accessing working capital was a key concern for MSMEs. Under normal circumstances, $50 \%$ of the respondents indicated accessing financing through bank loans, $46 \%$ from the founders' money, $14 \%$ from family and friends, and $7 \%$ from business revenue. Only $8 \%$ relied on external investors, and 10\% had accessed the Small and Medium-Sized Enterprise (SME) Fund and other government funds in the past. Women constituted $46 \%$ of those having accessed bank loans in the past, and $10 \%$ of rural and $2 \%$ of urban respondents had previously accessed SME support funds.

Access to working capital became more challenging during the crisis. This was mainly due to high collateral requirements for bank loans (identified by $60 \%$ of respondents), followed by high interest rates (50\%), short duration of loans (31\%), and delays in payments by partner companies (19\%). The absence of investors was identified as a challenge by $11 \%$ of respondents. Respondents also indicated that the lack of capital could delay their recovery prospects and would affect hiring or firing decisions (for 19\% of respondents), limit their capacity to plan for new product development (18\%), and affect other aspects of the business (11\%). Meanwhile, $11 \%$ of respondents reported no challenge.

\section{Figure 4: Coping Mechanisms among Mongolian Businesses, May-June 2020 (\%)}

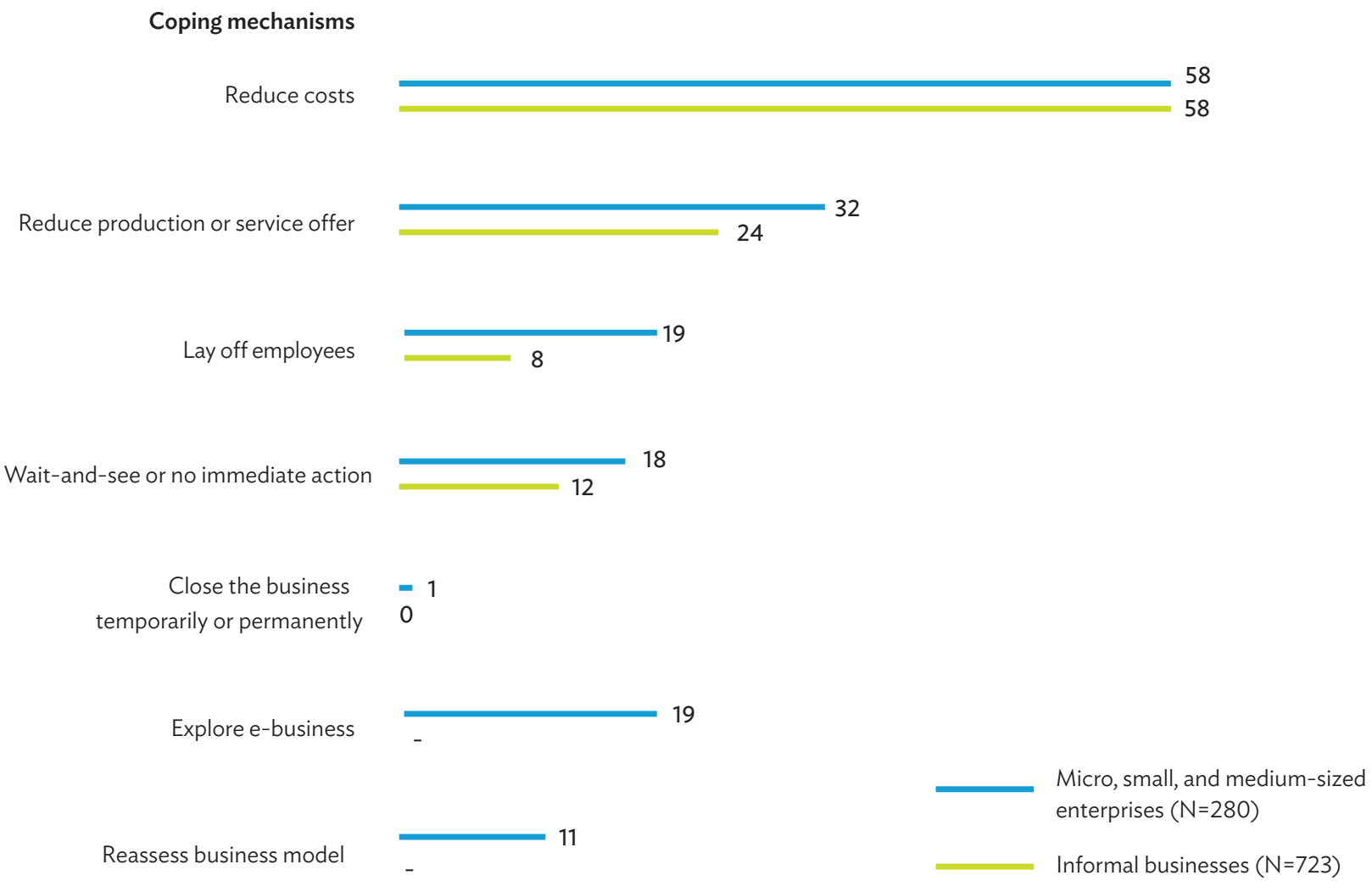

$\mathrm{N}=$ Total Responses.

Source: ADB East Asia Department. 
Over half of the informal businesses (54\%) indicated no financial capacity to overcome an extended crisis. The share was even higher for informal businesses in cities, $65 \%$ compared with $43 \%$ in rural areas. Overall, only $13 \%$ of the respondents indicated having bank deposits, less so in rural areas (10\% compared with $16 \%$ urban respondents), while only $20 \%$ reported bank loans as an option. Other options included financial support from family and friends (15\%), finding a new job (8\%), benefits from price increase of their products (6\%), access to donor organization funds (4\%), support from customers (3\%), and participation in public tenders (1\%).

\section{FEEDBACK ON THE GOVERNMENT'S ECONOMIC RESPONSE}

Approval of government measures was mixed. Government policies with the highest level of support included those that enabled businesses to maintain liquidity, including the 6-month exemption on social security contributions, personal income tax, and 6-month exemption on corporate income tax for small companies (Box). ${ }^{12}$ The reduction in fuel prices in line with the global fall in oil prices and the provision of subsidies for businesses to retain employees were also well received. Nonetheless, the specific circumstances of informal businesses were not reflected in the initial economic response. About a third of informal respondents opted for not assessing the economic measures aimed at businesses, arguing that these were not relevant to them. Furthermore, information regarding initial economic measures failed to reach many MSMEs and informal businesses (Figure 5).

(i) Support for the 6-month exemption on social security contributions and personal income tax was $45 \%$. More MSMEs (65\%) supported this measure than did informal businesses (37\%), likely as the latter often cannot afford to pay social security contributions, ${ }^{13}$ or because workers with low wages in informal businesses elect not to pay social contributions and prefer "cash at hand". However, $26 \%$ of the respondents reported no benefits from this measure, $3 \%$ had no knowledge, and 26\% elected not to answer. Even among MSMEs, 27\% did not expect to benefit and $8 \%$ indicated not knowing enough; while 68\% MSME female entrepreneurs were supportive compared to $56 \%$ of male entrepreneurs.

\section{Box: Fiscal and Monetary Responses to the COVID-19 Crisis}

\section{Fiscal Measures}

- The Government of Mongolia increased spending in the health sector to MNT17 billion ( $0.04 \%$ of gross domestic product).

- Selected food and medical items were exempted from import duties.

- Workers in the private sector were exempted from personal income tax for 6 months.

- Employees and employers were exempted from social security contributions for 6 months (extended by additional 3 months until the end of 2020).

- Micro, small, and medium-sized enterprises (MSMEs) with annual sales less than MNT1.5 billion were exempted from corporate income tax for 6 months (extended by an additional 3 months until the end of 2020).

- Soft loans to cashmere producers.

- Child money distribution was increased to MNT100,000 per month per child for 6 months (extended by additional 3 months until the end of 2020).

- Food stamps for poor individuals doubled for 6 months.

- Social welfare for the vulnerable groups increased for 6 months.

\section{Monetary Measures}

- The Bank of Mongolia cut the policy rate in March, April, and September 2020 by 1.0 percentage point each to $8.0 \%$.

- Local currency reserve requirement ratio was lowered by 200 basis points to $8.5 \%$.

- Interest rate corridor was narrowed to $\pm 1 \%$ from the policy rate.

- Consumer and housing mortgage loan repayments were deferred by 12 and 6 months, respectively.

- A temporary procedure to provide emergency loans to banks to support their liquidity position and ensure smooth functioning of the financial system was ratified.

- Asset classification and provisioning regulatory requirements for banks were eased.

- Minimum liquidity ratio of banks was reduced by 5.0 percentage points to $20 \%$.

- Effective date of new tier-I capital requirement for systemically important banks was postponed.

- Short-term foreign exchange swaps with banks were started to support their foreign exchange liquidity.

- Long-term foreign exchange swap agreements with banks were continued to support foreign exchange inflows.

- A new liquidity support instrument, the Long Term Repo, was launched to support liquidity in the financial sector.

Source: ADB East Asia Department.

12 Respondents assessed each government measure for its effectiveness in supporting the private sector. However, for some questions, 200-400 respondents (20\%-40\%) declined to answer because they considered the question as either irrelevant to their business or because they lacked sufficient information to respond. The government decision to defer the payments of personal loans and mortgage payment had not been announced during the implementation of the survey. Hence, the perception on this measure has not been assessed. Measures related to social transfers to vulnerable groups were not included in the survey.

13 Social security contributions stand at $24 \%$, with the company shouldering $12.5 \%$ and the employee $11.5 \%$. 
Figure 5: Perception of Government Response to COVID-19 (\%)

\begin{abstract}
Government measures in Mongolia during COVID-19

6-month exemption on social security contributions and personal income tax

Reduction in fuel prices
\end{abstract}

Corporate income tax exception for businesses with less than MNT1.5 billion in annual revenue

Salary subsidies of MNT200,000 per employee for entities that have experienced $50 \%$ or more decrease in revenues but retained employees

Subsidies for herders in the cashmere sector

Boost implementation of 14 large-scale infrastructure projects

\begin{tabular}{|l|l|l|l} 
Supports & $\begin{array}{l}\text { Does not support } \\
\text { or sees no direct } \\
\text { benefit }\end{array}$ & $\begin{array}{l}\text { Does not know } \\
\text { enough about this } \\
\text { measure }\end{array}$ & $\begin{array}{l}\text { No } \\
\text { response }\end{array}$ \\
\hline 45 & 26 & 326
\end{tabular}

\begin{tabular}{llll}
\hline 39 & 20 & 8 & 33
\end{tabular}

$\begin{array}{llll}29 & 33 & 6 & 32\end{array}$

$\begin{array}{llll}29 & 35 & 8 & 28\end{array}$

19 19 32

Note: $\mathrm{N}=1,0003$

Source: ADB East Asia Department.

(ii) Support for the corporate income tax exemption for all entities with less than MNT1.5 billion in annual revenue was $33 \%$. This measure had no impact on their businesses for $31 \%$ of the respondents, while $29 \%$ elected to skip this question, and another $7 \%$ reported not knowing enough. The approval for this measure was higher among MSMEs (52\%) than informal businesses (26\%), and higher among women in MSMEs (57\%) than other MSMEs (34\%).

(iii) Support for the salary subsidies of MNT200,000 per employee for entities that have suffered $50 \%$ or more reduction in revenues but retained jobs was $30 \%$. Some $33 \%$ reported no benefit from this measure, $32 \%$ elected not to answer, and $6 \%$ did not know enough. Among MSMEs, support was mixed with $40 \%$ reporting benefit from salary subsidies, and an equal share reporting no benefit, while a further $20 \%$ were unsure. Women entrepreneurs were more supportive (43\%) than male entrepreneurs (33\%). Only $25 \%$ of informal respondents supported this measure, $30 \%$ indicated no benefit, and $44 \%$ elected not to respond.

(iv) Support for subsidies for herders in the cashmere sector was at $29 \%$. This measure supported companies in the cashmere sector with 3\% loans to maintain exports. Rural MSMEs had a higher rate of approval (37\%) than urban ones (27\%). Among informal entrepreneurs, $28 \%$ supported the measure, $29 \%$ expected no impact from it, and $39 \%$ elected not to answer. However, lack of demand from Europe, border closures with the People's Republic of China, and a sharp contraction in international tourism could have offset gains from this measure.

(v) Support for reduced fuel prices in line with significantly lower international oil prices stood at 39\%. Twenty percent of respondents indicated no impact, and another $8 \%$ were unsure of the impact. Local travel restrictions and general reduction of business activities reduced the impact of this measure. Among MSMEs, 55\% indicated that this measure benefits their operation, 33\% informal entrepreneurs supported it, and $44 \%$ elected not to answer.

(vi) Support for implementation of 14 large projects to support the economy was at $19 \%$. These are primarily infrastructure projects with a long-term impact on the economy. However, a similar share did not support; $30 \%$ indicated not knowing enough about it; and 32\% chose not to respond. 
Only $20 \%$ of the respondents indicated a good understanding of the economic measures. A further $47 \%$ indicated having general understanding but needed further clarifications, $12 \%$ had no knowledge, and $21 \%$ elected not to answer. Among MSMEs, $89 \%$ indicated a good or general understanding, compared to $59 \%$ from the informal respondents. Among informal respondents, 13\% reported no knowledge, and 29\% decided not to answer arguing lack of relevance to their needs - this percentage was higher among women (33\%).

\section{ADDITIONAL ECONOMIC MEASURES REQUESTED BY ENTREPRENEURS}

Access to finance remains a priority for smaller enterprises, both formal and informal. Proposals to facilitate this access included soft loans (either as unsecured low interest loans in line with taxes paid in 2019), long-term mortgage programs for businesses, dedicated business funds, long-term investment loans, short-term revolving credit lines for working capital, and trade finance support.

Further tax exemptions were requested, which have been included in revised measures such as extended corporate income tax and personal income tax exemptions until the end of 2020; as well as additional value-added tax and customs duties exemptions on selected goods. Figure 6 summarizes the measures requested by entrepreneurs.

\section{PATHWAYS FOR RECOVERY: AREAS OF ACTION}

The rapid action of government to support the Mongolian population and businesses has been remarkable. It prevented a large-scale health crisis and cushioned Mongolians from the worst of the economic shock. However, the pandemic will remain a part of life well into 2021 and measures going forward can benefit from the lessons learned so far. The economy is cautiously reopening, but has since November entered a second lockdown.

The overarching recommendation based on the findings of this rapid assessment is that economic recovery will require a dedicated focus on the recovery of smaller businesses in the formal and informal sectors, as well as promoting their resilience in the medium term. Three areas of action are presented below to ensure that SMEs and formal and informal micro businesses can overcome this difficult time (Figure 7).

\section{Maintain options to preserve liquidity and enhance access to finance}

(a) Short-term actions. The government has extended the corporate tax and value-added tax (VAT) exceptions on certain goods, and has reduced social security contributions until the end of 2020. Social protection measures (e.g., child money program, food stamps) that are critical to support households and the most vulnerable have also been extended until the end of 2020. As the crisis evolves, measures to protect workers in the event of a possible second wave during winter should include a continuation of the employee salary subsidies for micro and small entities that retain or create new jobs. To boost demand, fiscal measures can be complemented with a mix of incentives in key sectors such as tourism, food processing, and practical support; including provision of subsidized personal protective equipment, disinfection inputs, and guidelines to ensure safe business operations.

(b) Medium-term remedies. The Law on the Credit Guarantee Fund of Mongolia should be amended. Amendments will enable the fund to expand its guarantee product menu and ensure sustainable state budget funding to raise its capital and reserve fund to cope with the expansion of the guarantee product menu. The new legislation can enable the Credit Guarantee Fund mechanism to offer portfolio-level guarantees for new loans to SMEs for refinancing or working capital finance, and for existing SME loans.

(c) Institutionalize and roll out the SME Agency. ${ }^{14}$ This is to provide transparent and more efficient procedures to enable rapid access to funds; and to act as a onestop-shop for MSMEs, providing regulatory, business advisory, and market research services.

(d) Support affordable and inclusive access to finance for micro and informal businesses. Demand for affordable finance for micro and informal businesses remains unmet. Mongolia has an established microfinance structure that includes XacBank, Khan Bank, TransCapital, and Vision Fund as leaders in the field, plus a large number of smaller institutions. Some have introduced innovative financing, including supply-chain finance (XacBank), and financial technology or fintech services (Khan Bank through LendMN). Fintech is growing, and the pandemic has only highlighted its potential. To enhance inclusive financing, the Government of Mongolia and Bank of Mongolia need to work on options for wholesale funding to increase access for micro and informal businesses, and promote the fintech sector and the necessary ecosystem in the country to maximize its potential.

(e) Support for specific financial needs of womenled MSMEs. Those clustered in hard-hit sectors vulnerable to competition from imports (e.g., food processing, garment manufacturing) would benefit most from this. The pandemic has highlighted the importance of formalizing a definition for women-

14 The previous SME Development Fund has been dissolved and reorganized into the SME Agency in August 2020, per Resolution \#49 of the Government of Mongolia. SME Agency is an implementing agency under the Ministry of Food, Agriculture and Light Industry. 
Figure 6: Suggested Additional Measures the Government of Mongolia Can Take to Support Businesses

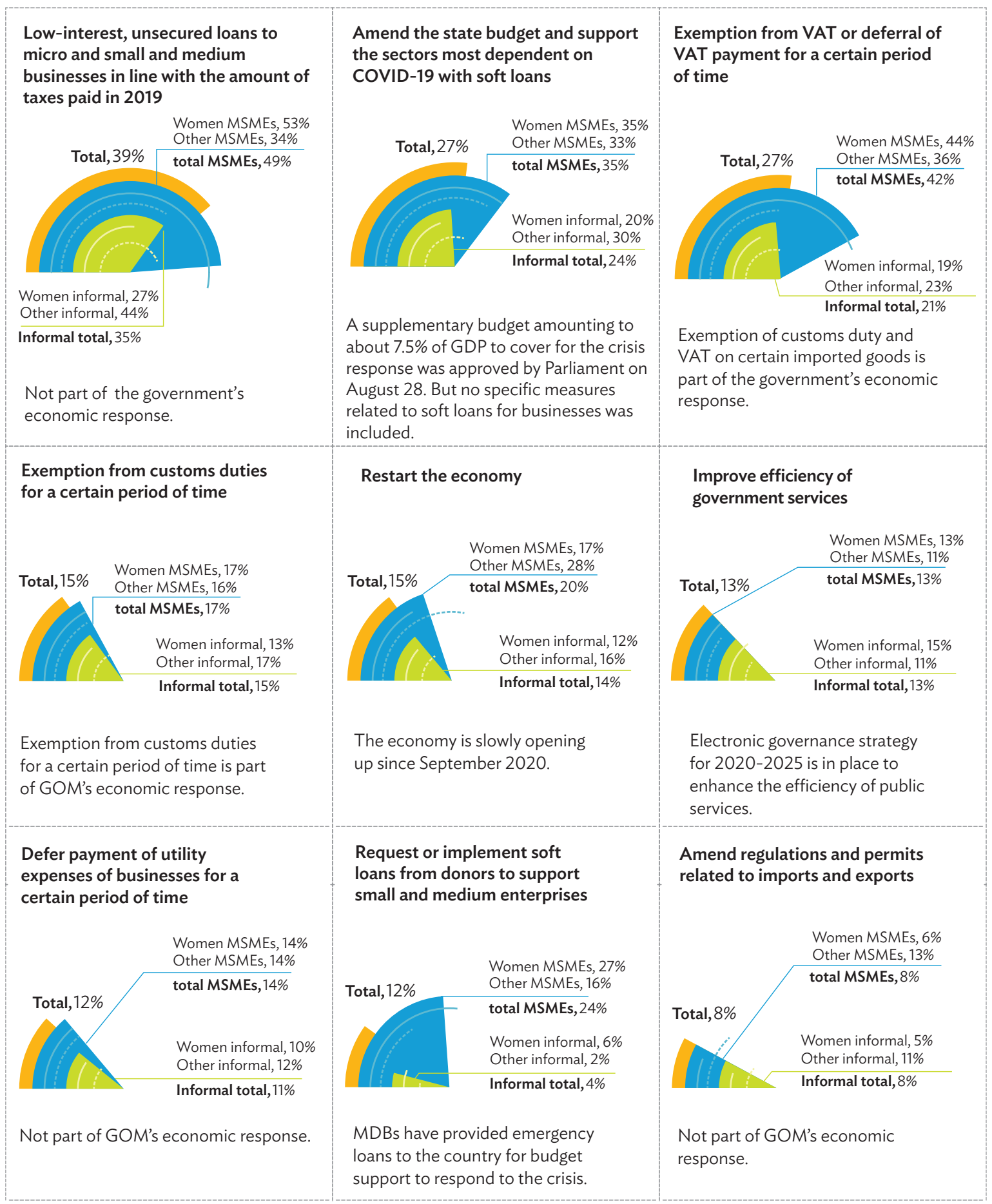

MSMEs = micro, small, and medium-sized enterprises; GDP = Gross Domestic Product; MDBs= multilateral development banks; VAT = value-added tax . Note: $\mathrm{N}=1,0003$.

Source: ADB East Asia Department. 
Figure 7: Recommended Areas to Support Businesses

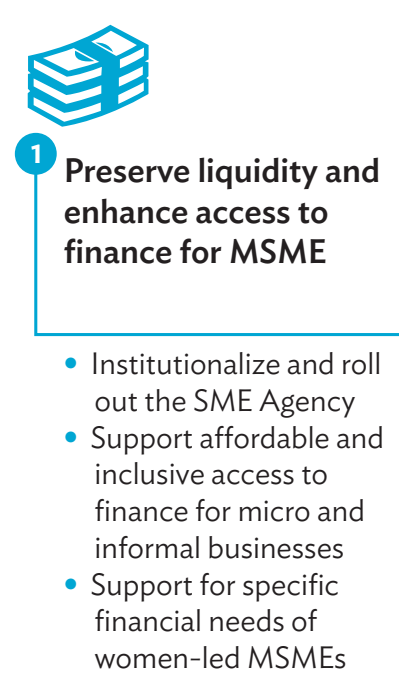

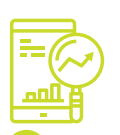

Help MSMEs to grasp opportunity and push forward

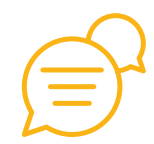

Communicate the medium- and long-term response to MSME

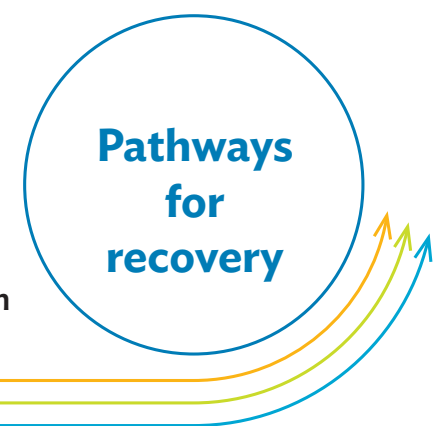

- Enable small businesses to expand to a digital environment

- Promote business development services

- Support nonmining sector value chain creation

- Promote youth innovation and the development of entrepreneurial skills

- A path toward formality for informal business
- Engage and maintain fluid communication

- Keep the business community informed

- Continue monitoring impacts as the crisis evolves women-led MSMEs

MSME = micro, small, and medium-sized enterprises, $S M E$ = small and medium-sized enterprises .

Source: ADB East Asia Department.

owned business appropriate to the Mongolian context, and improving gender statistics to increase the chances of female entrepreneurs to access support programs during emergencies and beyond.

\section{Help MSMEs do what they do best, which is to grasp opportunity and push forward}

(a) Enable small businesses to expand to a digital environment. Mongolia has good conditions to accelerate e-commerce-from extensive mobile accessibility even in rural areas; affordable internet access; to a growing e-commerce ecosystem, including online platforms and e-payment options. ${ }^{15}$ COVID-19 has demonstrated the need for a digital acceleration. The challenge is to ensure that smaller and informal businesses can enter and operate in this space, and to account for the potential digital divide among urban and rural businesses and businesses run by women.

(b) Promote business development services. These include services that connect businesses, such as digital business-to-business marketplaces that link larger companies to MSME suppliers. For example, along the food supply chain in rural areas, support can be given to smaller businesses to organize into cooperatives, and training can be promoted to improve overall business capacity (financial planning, logistics management, product standardization and quality, green transition, e-commerce).

(c) Support nonmining sector value chain creation. The dependence on the mining sector for income and taxes have obscured support for other sectors that generate jobs and productivity. The significant share of women in the informal sector and high youth unemployment reflect the shift in the economic structure. This requires continued support for value chain creation and cluster development in nonmining sectors. Creation of cooperatives in the agriculture sector and supporting SMEs in linking and lifting these cooperatives is a backbone of value chain development.

(d) Promote youth innovation and the development of entrepreneurial skills. Accelerator programs

15 Communications Regulatory Commission of Mongolia. 2018. Main Indicators of ICT Sector 2018. https://crc.gov.mn/en/k/S/11. 
can support young entrepreneurs; provide them with necessary skills; help them access seed funding; and provide spaces for developing critical thinking, problem solving, project management, and communication and digital skills.

(e) For informal business, a path toward formality can be a way to build back stronger. This can be achieved by reducing tax and regulatory burdens, such as lowering business registration fees; providing limited exemptions to business registration tax for newly established businesses; and legal and business advice and training, paving the way for registration.

\section{Communicate, inform, and engage businesses for the medium- and long-term response}

(a) Engage and maintain fluid communication with the private sector. $\mathrm{MNCCl}$ can play an active role for the joint formulation of evidence-based policy response and further economic measures for recovery, which will resonate with beneficiaries and respond to their varying needs.

(b) Keep the business community informed.

The business community has to be abreast of government action through communication channels that can reach the diverse business segments, including smaller businesses that need the most support. Engage media, $\mathrm{MNCCl}$, industry associations, non-governmental organizations, including those engaged in the field of women's economic empowerment, in disseminating information on emergency and recovery measures to ensure that all participants in the economy receive equal support from the government. The use of a digital platform as a single source of information on government policies and measures should be considered.

(c) Continue monitoring impacts as the crisis evolves. This includes surveys such as the one presented in this brief to obtain a good understanding of the issues and needs of the diverse business segments in the country, including MSMEs, informal sector, rural and urban businesses, and businesses owned by women.
About the Asian Development Bank

ADB is committed to achieving a prosperous, inclusive, resilient, and sustainable Asia and the Pacific, while sustaining its efforts to eradicate extreme poverty. Established in 1966, it is owned by 68 members49 from the region. Its main instruments for helping its developing member countries are policy dialogue, loans, equity investments, guarantees, grants, and technical assistance.

ADB Briefs are based on papers or notes prepared by ADB staff and their resource persons. The series is designed to provide concise, nontechnical accounts of policy issues of topical interest, with a view to facilitating informed debate. The Department of Communications administers the series.

Note: In this publication, "MNT" refers to togrog.
The views expressed in this publication are those of the authors and do not necessarily reflect the views and policies of ADB or its Board of Governors or the governments they represent. ADB encourages printing or copying information exclusively for personal and noncommercial use with proper acknowledgment of ADB. Users are restricted from reselling, redistributing, or creating derivative works for commercial purposes without the express, written consent of ADB.

Asian Development Bank

6 ADB Avenue, Mandaluyong City

1550 Metro Manila, Philippines

Tel +63286324444

Fax +63286362444

www.adb.org/publications/series/adb-briefs 